\title{
Ritual Sajen pada Penganut Sunda Wiwitan (Studi Komunikasi Budaya pada Penganut Sunda Wiwitan)
}

\author{
Melina, Suzy S. Azeharie \\ melina.915160201@stu.untar.ac.id,suzya@fikom.untar.ac.id
}

Fakultas Ilmu Komunikasi Universitas Tarumanagara

\begin{abstract}
Sunda Wiwitan is a belief held by traditional Sundanese society or native Sundanese religion. Sundanese Wiwitan community is spread in West Java, one of which is Cigugur Village, Kuningan. In carrying out their religious activities, this group usually presents offerings. The rituals of offerings in Sunda Wiwitan have existed since the stone age. This ritual is a legacy from the ancestors handed down to the younger generation of Sunda Wiwitan through the communication process. This ritual is still carried out by the Sunda Wiwitan community until this day. The purpose of this research is to find out how the process of offering rituals on Sunda Wiwitan adherents and what are the preparations needed at the time of the ritual. Theories used in this research are communication theory, culture and ritual communication. The research method used was a descriptive qualitative research method with a phenomenological method. The data to be analyzed was obtained from the results of in-depth interviews with three speakers. The conclusion from this study is that ritual offerings are not a negative thing. But the offerings ritual is a ritual that presents the work of human beings to Sang Hyang Kersa or the Creator, creatures that appear or do not appear as expressions of gratitude and. This ritual is also a symbol that describes the relationship between humans and nature and humans with the Creator.
\end{abstract}

Keywords: culture, communication, ritual communication, ritual sajen, sunda wiwitan

\begin{abstract}
Abstrak
Sunda Wiwitan merupakan sebuah aliran kepercayaan yang dianut oleh masyarakat tradisional Sunda atau agama Sunda asli. Masyarakat penganut Sunda Wiwitan tersebar di daerah Jawa Barat salah satunya adalah Desa Cigugur, Kuningan. Dalam menjalankan kegiatan agamanya kelompok ini biasa menyajikan sajen. Ritual sajen dalam Sunda Wiwitan sudah ada sejak zaman batu. Ritual ini merupakan warisan dari para leluhur yang diturunkan kepada generasi muda Sunda Wiwitan melalui proses komunikasi. Ritual ini masih dilaksanakan oleh masyarakat Sunda Wiwitan sampai saat ini. Tujuan dari penelitian ini adalah untuk mengetahui bagaimanakah proses ritual sajen pada penganut Sunda Wiwitan dan apa saja persiapan yang dibutuhkan pada saat ritual sajen dilakukan. Teori yang digunakan dalam penelitian ini adalah teori komunikasi, budaya dan komunikasi ritual. Metode penelitian yang digunakan adalah metode penelitian kualitatif deskriptif dengan metode fenomenologi. Data yang akan dianalisis diperoleh dari hasil wawancara mendalam dengan tiga orang narasumber. Kesimpulan dari penelitian ini adalah ritual sajen bukanlah sebagai suatu hal yang negatif. Tetapi ritual sajen merupakan ritual yang mempersembahkan hasil karya olah manusia kepada Sang Hyang Kersa atau Sang Pencipta, makhluk yang tampak maupun tidak tampak sebagai ucapan rasa syukur dan terima kasih. Ritual sajen juga merupakan simbol yang menggambarkan hubungan antara manusia dengan alam dan manusia dengan Sang Pencipta.
\end{abstract}

Kata Kunci: budaya, komunikasi, komunikasi ritual, ritual sajen, sunda wiwitan. 


\section{Pendahuluan}

Indonesia dikenal sebagai masyarakat yang majemuk. Hal ini terlihat dari semboyan Bhinneka Tunggal Ika yang artinya berbeda-beda tetapi tetap satu. Kemajemukan yang ada terdiri atas keragaman suku bangsa, budaya, ras, agama dan bahasa. Berdasarkan data Badan Pusat Statistik tahun 2010, Indonesia memiliki lebih dari 300 kelompok suku bangsa dan terdapat 1.340 suku bangsa dan enam kepercayaan resmi yang diakui oleh pemerintah yaitu Islam, Kristen, Katolik, Hindu, Buddha dan Konghucu (sumber: https://www.indonesia.go.id/profil/suku-bangsa diakses pada tanggal 11 Oktober 2019 pukul 16.08 WIB).

Sampai saat ini masih ada ratusan kepercayaan tradisional yang sampai saat ini masih eksis di masyarakat. Salah satu bentuk kepercayaan tradisional adalah Sunda Wiwitan. Ira Indrawardana mengatakan bahwa Sunda Wiwitan adalah panggilan atau penamaan terhadap masyarakat Sunda yang masih mempertahankan ajaran turun temurun dari para leluhur Sunda (hasil wawancara terhadap Ira Indrawardana via WhatsApp pada tanggal 30 Oktober 2019).

Sampai saat ini karena penganut Sunda Wiwitan belum masuk ke dalam enam agama yang diakui oleh pemerintah maka mereka dialienasi oleh masyarakat. Hal ini penulis lihat ketika penulis melakukan pra observasi dan melakukan wawancara terhadap Pangeran Gumirat Barna Alam yang merupakan ketua adat masyarakat Sunda Wiwitan. Pangeran Gumirat Barna Alam menjelaskan bahwa mereka mendapat pengucilan dari masyarakat luar karena kepercayaan yang mereka anut tidak diakui oleh pemerintah dan dianggap masih mengandung hal-hal yang mistis (hasil wawancara terhadap Pangeran Gumirat Barna Alam yang dilakukan pada tanggal 21 September 2019 pukul 08.52 WIB).

Dalam kepercayaan Sunda Wiwitan dikenal sebuah ritual yang masih dilakukan hingga saat ini yaitu ritual Sajen. Ritual sajen adalah sebuah ritual yang memberikan sajian kepada Sang Hyang Karsa untuk memohon agar dilindungi dari segala roh jahat dan juga sebagai bentuk ucapan terimakasih kepada para leluhur dan kepada alam.

Menurut Cassandra L. Book dalam Hafied Cangara mendefinisikan komunikasi adalah suatu transaksi, proses simbolik yang menghendaki orang-orang mengatur lingkungannya dengan membangun hubungan antar sesama manusia melalui pertukaran informasi, untuk menguatkan sikap dan tingkah laku orang lain serta berusaha mengubah sikap dan tingkah laku itu (Cangara, 2018).

Deddy Mulyana dan Jalaluddin Rakhmat mendefinisikan budaya sebagai tatanan pengetahuan, pengalaman, kepercayaan, nilai, sikap, makna, hirarki, konsep alam semesta dan objek-objek materi yang dimiliki oleh sekelompok besar orang dari generasi ke generasi melalui usaha individu dan kelompok (Mulyana dan Rakhmat, 2010).

Budaya sangat erat hubungannya dengan komunikasi. Suzy S. Azeharie, Sinta Paramita dan Wulan Purnama Sari dalam jurnalnya mengatakan bahwa komunikasi dan kebudayaan merupakan suatu kesatuan integral yang tidak dapat berdiri sendiri (Azeharie, et.al, 2019).

Salah satu tujuan komunikasi adalah mempertahankan budaya agar dapat diwariskan ke generasi penerus. Tanpa adanya komunikasi, budaya tidak dapat diwariskan secara turun temurun dari satu generasi ke generasi lain. Hal ini sesuai dengan pendapat Dadan Anugrah dan Winny Kresnowati yang mengungkapkan bahwa budaya dan komunikasi berinteraksi secara erat dan dinamis. Inti budaya adalah 
Melina, Suzy S Azeharie: Ritual Sajen pada Penganut Sunda Wiwitan (Studi Komunikasi Budaya pada Penganut Sunda Wiwitan)

komunikasi karena budaya muncul melalui komunikasi (Anugrah dan Kresnowati, 2008).

Masih dalam buku yang sama, Dadan Anugrah dan Winny Kresnowati menjelaskan bahwa budaya yang tercipta akan akan mempengaruhi cara berkomunikasi anggota budaya yang bersangkutan. Hubungan antara budaya dan komunikasi adalah timbal balik. Budaya tidak akan eksis tanpa komunikasi dan sebaliknya komunikasi pun tidak akan eksis tanpa adanya peranan budaya (Anugrah dan Kresnowati, 2008).

Tujuan dari penelitian ini adalah untuk mengetahui bagaimanakah proses ritual sajen pada masyarakat penganut Sunda Wiwitan di Desa Cigugur, Kuningan dan untuk mengetahui apa saja perlengkapan dan persiapan pada saat ritual sajen dilakukan. Alasan lainnya adalah karena penelitian mengenai ritual sajen pada penganut Sunda Wiwitan belum ada yang meneliti sebelumnya.

\section{Metode Penelitian}

Metode yang digunakan dalam penelitian ini yaitu kualitatif deskriptif dengan pendekatan fenomenologi. Menurut Lexy J. Moleong, metode penelitian kualitatif merupakan penelitian yang bertujuan untuk memahami fenomena yang dialami oleh subjek penelitian misalnya perilaku, persepsi, motivasi dan tindakan secara holistik dengan cara deskripsi dalam bentuk kata-kata dan bahasa pada suatu konteks khusus yang alamiah dengan memanfaatkan berbagai metode alamiah (Moleong, 2009).

Menurut Engkus Kuswarno, fenomenologi merupakan ilmu yang menjelaskan dan mengklasifikasikan fenomena atau studi tentang fenomena. Dengan kata lain fenomenologi mempelajari fenomena yang tampak di depan dan di masa yang akan datang (Kuswarno, 2009). Masih dalam buku yang sama John W. Creswell juga menambahkan bahwa pengumpulan data dalam fenomenologi dapat dilakukan dengan cara wawancara (Kuswarno, 2009).

Teknik pengumpulan data dalam penelitian ini dilakukan dengan cara wawancara mendalam terhadap tiga orang narasumber yaitu Ketua Adat dan pendamping Ketua Adat masyarakat penganut Sunda Wiwitan dan salah satu masyarakat penganut Sunda Wiwitan. Teknik pengumpulan data juga dilakukan dengan cara studi kepustakaan dan penelusuran data online.

\section{Hasil Temuan dan Diskusi}

\section{Ritual Sajen}

Kebiasaan atau tradisi ritual sajen sudah ada sejak zaman megalitikum atau batu besar. Sajen merupakan hasil olah karya manusia yang dihidangkan sebagai bentuk penghargaan kepada Sang Hyang Kersa atau Sang Pencipta. Selain itu sajen juga diberikan kepada makhluk yang tidak tampak dan hewan kecil yang tampak seperti semut, belalang yang ikut mencicipi hasil karya manusia. Jadi makna sajen cukup adiluhung atau mulia karena kehalusan dan kepekaan rasa terhadap sang maha pencipta dan ciptaan lainnya (wawancara dengan Pangeran Gumirat di Cigugur, Kuningan pada tanggal 21 September 2019 pukul 08.30 WIB).

Sementara menurut Subrata ritual sajen merupakan sebuah tradisi peninggalan nenek moyang yang berbentuk simbol. Ritual sajen merupakan sebuah simbol untuk menyampaikan rasa terima kasih kepada segala ciptaan di muka bumi. Selain itu ritual sajen merupakan cara menyampaikan rasa terima kasih kepada Sang Pencipta. 
Masyarakat penganut Sunda Wiwitan juga diajarkan mengerti mengenai apa yang disajenkan atau dipersembahkan (wawancara dengan Subrata di Cigugur, Kuningan pada tanggal 21 September 2019 pukul 10.25 WIB).

Ritual Sajen menurut Ira Indrawardana adalah sesuatu yang penting yang terkait dengan ritual adat misalnya upacara adat yang bersifat seremonial dan juga ritual yang diadakan oleh keluarga. Ritual sajen sangat penting karena merupakan sebuah tradisi turun temurun dan sebagai masyarakat adat wajib untuk menjaga kelestariannya (wawancara dengan Ira Indrawardana via WhatsApp pada tanggal 30 Oktober 2019 pukul 12.15 WIB).

\section{Komponen Komunikasi Ritual}

Menurut Koentjaraningrat ada empat komponen pokok yang terdapat dalam pelaksanaan ritual yaitu:

a. Tempat berlangsungnya ritual

Tempat yang digunakan untuk melaksanakan suatu ritual adalah tempat khusus yang bersifat keramat dan hanya orang berkepentingan saja yang boleh menggunakan tempat tersebut (Koentjaraningrat, 1967).

Berdasarkan hasil wawancara dengan Pangeran Gumirat tempat berlangsungnya ritual sajen adalah di ruangan pendopo yang merupakan tempat berkumpul dan berdoa masyarakat penganut Sunda Wiwitan dan tempat letak singgasana Pangeran Madrais yang merupakan pendiri kepercayaan Sunda Wiwitan (wawancara dengan Pangeran Gumirat di Cigugur, Kuningan pada tanggal 21 September 2019 pukul 08.30 WIB).

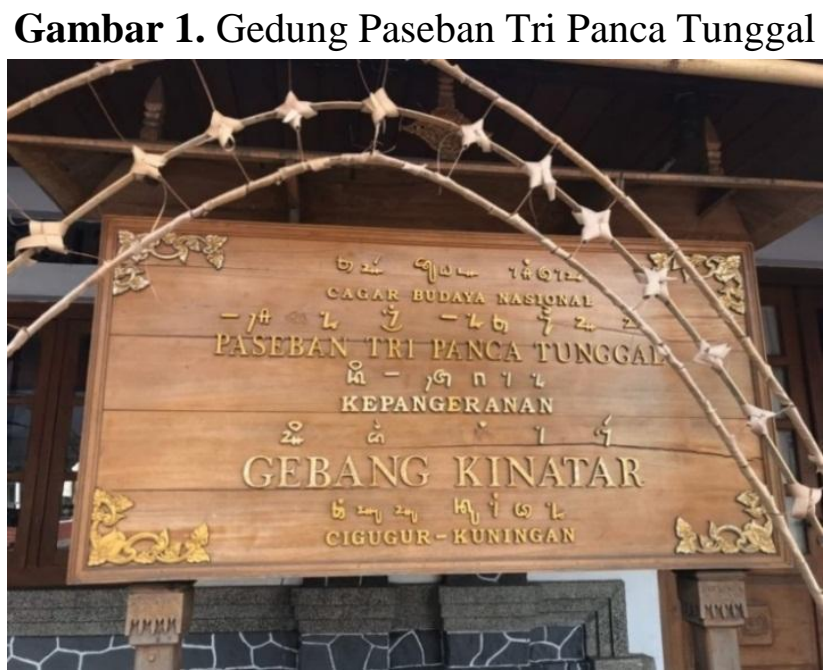

Sumber: Dokumentasi Penulis 


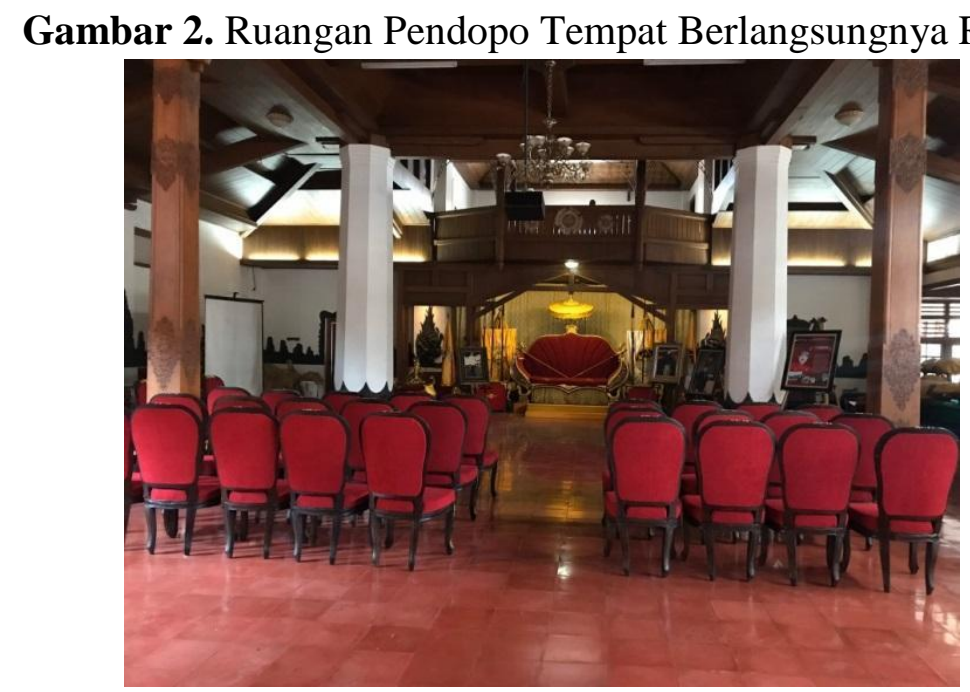

Sumber: Dokumentasi Penulis

b. Waktu pelaksanaan ritual

Waktu pelaksanaan ritual adalah saat-saat tertentu yang dirasakan tepat untuk melaksanakan suatu ritual (Koentjaraningrat, 1967). Pangeran Gumirat mengatakan bahwa ritual sajen dilakukan sebelum diadakannya acara besar seperti Seren Taun. Seren Taun merupakan upacara adat panen padi yang setiap tahun dilakukan oleh masyarakat Sunda Wiwitan. Upacara ini merupakan bentuk rasa syukur atas hasil panen padi kepada Sang Pencipta (wawancara terhadap Pangeran Gumirat di Cigugur, Kuningan pada tanggal 21 September 2019 pukul 08.30 WIB).

Sementara Ira Indrawardana mengatakan bahwa ritual sajen dapat dilakukan sebelum acara ulang tahun, acara syukuran atas kelahiran, acara pernikahan. Pada saat acara tersebut akan disediakan nasi tumpeng, teh pahit, teh manis, kopi pahit dan kopi manis. Hal tersebut juga termasuk sebagai bentuk sajen (wawancara terhadap Ira Indrawardana via WhatsApp pada tanggal 30 Oktober 2019 pukul 12.15 WIB).

c. Benda-benda ritual

Benda-benda ritual merupakan alat-alat yang digunakan dalam menjalan suatu ritual seperti wadah untuk tempat sajen, alat kecil seperti sendok, pisau dan lain-lain (Koentjaraningrat, 1967). Pangeran Gumirat menjelaskan bahwa benda-benda ritual adalah barang-barang atau perlengkapan yang digunakan pada saat ritual sajen. Bendabenda ritual pada saat ritual sajen adalah pakaian putih untuk perempuan, pakaian hitam untuk laki-laki, nampan yang terbuat dari bambu, teh manis, teh pahit, kopi manis, kopi pahit, air putih, nasi congcot, pengikat kepala berbentuk segi empat (wawancara dengan Pangeran Gumirat di Cigugur, Kuningan pada tanggal 21 September 2019 pukul 08.30 WIB).

Subrata mengatakan selain benda-benda yang disebutkan di atas, terdapat benda-benda lainnya yaitu kerupuk berwarna putih dan merah, pisang, rujakan, ketupat yang memiliki lima sisi, bakakak ayam, bunga tujuh warna, telur asin dan kujang yang menancap di atas kelapa (wawancara dengan Subrata di Cigugur, Kuningan pada tanggal 21 September 2019 pukul 10.25 WIB). 
Gambar 3. Perlengkapan Ritual Sajen

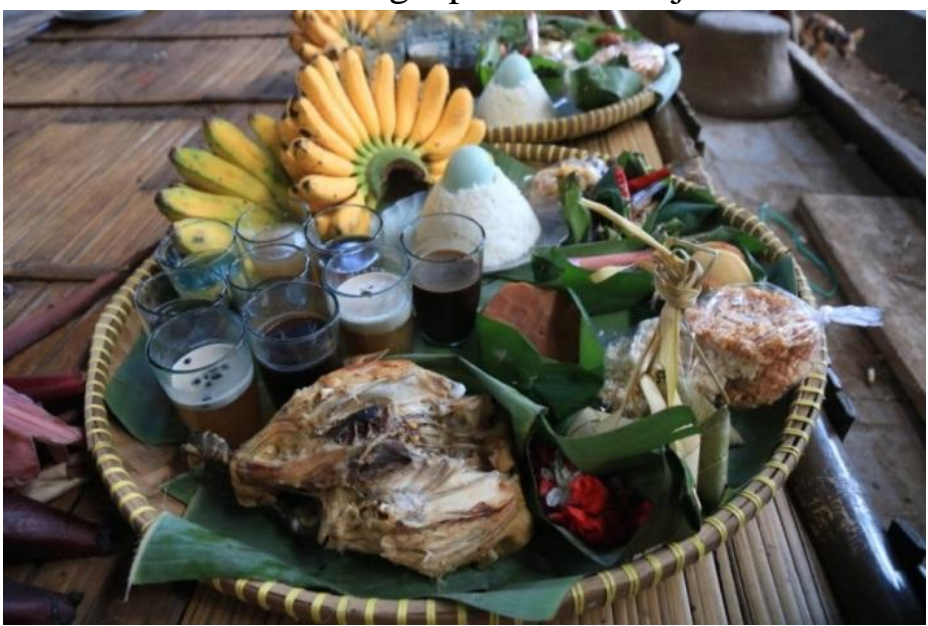

Sumber: Dokumentasi Pangeran Gumirat

d. Orang-orang yang terlibat dalam ritual

Orang-orang yang terlibat dalam ritual adalah orang yang bertindak sebagai pemimpin jalannya ritual dan orang yang paham tentang suatu ritual (Koentjaraningrat, 1967).

Berdasarkan hasil wawancara penulis dengan Pangeran Gumirat orang-orang yang terlibat dalam ritual adalah Ketua Adat masyarakat penganut Sunda Wiwitan, para ais pangampih dan masyarakat penganut Sunda Wiwitan mulai dari anak kecil dan orang dewasa (wawancara dengan Pangeran Gumirat di Cigugur, Kuningan pada tanggal 21 September 2019 pukul 08.30 WIB).

Gambar 4. Orang-orang yang terlibat

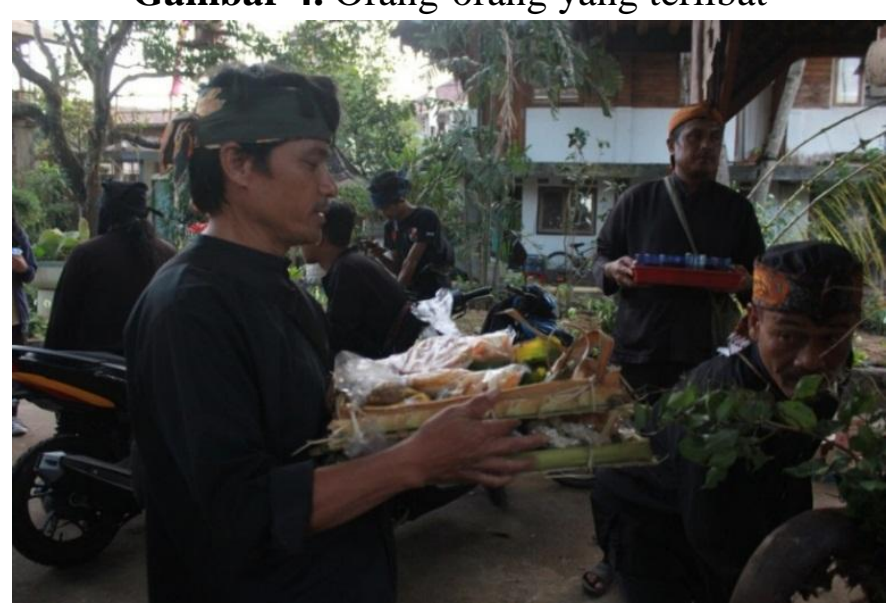

Sumber: Dokumentasi Pangeran Gumirat

Masih dalam buku yang sama Koentjaraningrat menjelaskan terdapat dua indikator perbuatan yang terkait dalam pelaksanaan suatu ritual yaitu:

a. Berdoa

Berdoa adalah unsur yang terdapat dalam berbagai ritual. Doa adalah ucapan dari keinginan manusia kepada para leluhur dan juga doa merupakan ucapan hormat dan pujian kepada para leluhur. Biasanya doa diiringi dengan gerak dan sikap menghormat serta merendahkan diri terhadap para leluhur (Koentjaraningrat, 1967). 
Hal ini sesuai dengan yang dijelaskan oleh Pangeran Gumirat bahwa sajen yang akan disajikan didoakan terlebih dahulu secara bersama-sama dan dipimpin oleh Ketua Adat dan para ais pangampih di ruangan pendopo Gedung Paseban. Doa yang dipanjatkan berisi pengaharapan dan permohonan agar diberi keberkahan dan keselamatan (wawancara dengan Pangeran Gumirat di Cigugur, Kuningan pada tanggal 21 September 2019 pukul 08.30 WIB).

b. Bersaji

Bersaji adalah perbuatan-perbuatan untuk menyajikan makanan, benda-benda atau yang lainnya kepada dewa-dewa dan roh-roh nenek moyang. Bersaji menjadi suatu kebiasaan dan dianggap sebagai suatu aktivitas yang secara otomatis akan menghasilkan apa yang di maksud (Koentjaraningrat, 1967).

Pangeran Gumirat menjelaskan bahwa setelah sajen didoakan, sajen dibawa keluar dan diletakkan di dalam lumbung padi, di empat penjuru arah mata angin, di delapan penjuru arah mata angin (wawancara dengan Pangeran Gumirat di Cigugur, Kuningan pada tanggal 21 September 2019 pukul 08.30 WIB).

\section{Informasi Mengenai Ritual Sajen Diturunkan Kepada Generasi Muda}

Menurut Pangeran Gumirat, informasi mengenai ritual sajen diturunkan kepada generasi muda penganut Sunda Wiwitan karena ritual sajen penting dan merupakan amanat dari para leluhur. Informasi mengenai ritual ini diturunkan kepada generasi muda melalui pertemuan yang dilaksanakan setiap hari Sabtu pukul 19.00 sampai pukul 21.00 WIB di Gedung Paseban Tri Panca Tunggal. Para anak-anak dan remaja dikumpulkan di Gedung Paseban dan diberikan pendidikan budi pekerti serta pengetahuan mengenai ritual sajen oleh Ketua Adat (wawancara dengan Pangeran Gumirat di Cigugur, Kuningan pada tanggal 21 September 2019 pukul 08.30 WIB).

Sementara menurut Subrata, informasi mengenai ritual sajen telah diajarkan kepada anaknya sejak kecil. Setiap ada ritual sajen ia selalu mengikutsertakan anakanaknya agar mereka mengerti dan ikut menjaga tradisi tersebut. Tetapi karena anaknya sudah ada yang menikah dan pindah ke Bandung, anak-anaknya sudah jarang mengikuti ritual tersebut (wawancara terhadap Subrata di Cigugur, Kuningan pada tanggal 21 September 2019 pukul 10.25 WIB).

Sejalan dengan Pangeran Gumirat dan Subrata, Ira Indrawardana mengatakan bahwa secara umum ritual sajen diturunkan kepada generasi muda karena melalui pelaksanaan ritual sajen orang mengetahui dan menyaksikan bahwa ritual ini merupakan ajaran dan amanat dari leluhur dan sebagai warga adat wajib untuk melestarikan tradisi yang sudah turun temurun. Ritual sajen juga merupakan media yang menyimbolkan hubungan antara manusia dengan para leluhur dan Sang Pencipta (wawancara dengan Ira Indrawardana via WhatsApp pada tanggal 30 Oktober 2019 pukul 21.15 WIB).

\section{Simpulan}

Komunikasi budaya merupakan komponen yang penting dalam mewariskan budaya ritual sajen. Dengan adanya komunikasi budaya masyarakat penganut Sunda Wiwitan dapat mewariskan dan mempelajari pesan dan makna yang terkandung dalam ritual sajen. Ritual sajen merupakan sebuah ritual yang mempersembahkan hasil karya olah manusia kepada Sang Hyang Kersa atau Sang Pencipta, kepada makhluk yang tampak maupun yang tidak tampak sebagai bentuk penghargaan dan ucapan terima 
kasih. Ritual sajen merupakan media yang menggambarkan hubungan antara manusia dan Sang Pencipta dan hubungan manusia dan alam.

\section{Ucapan Terima Kasih}

Penulis mengucapkan terima kasih kepada kedua orang tua dan kakak penulis, narasumber yang telah bersedia meluangkan waktunya serta semua pihak yang telah memberikan dukungan dan bantuan kepada penulis selama proses penyusunan jurnal penelitian ini.

\section{Daftar Pustaka}

Anugrah, Dadan dan Kresnowati. (2008). Komunikasi Antarbudaya Konsep dan Aplikasinya. Jakarta: Jala Permata

Azeharie, Suzy., Sinta Paramita dan Wulan Purnama Sari. (2019). Studi Budaya Nonmaterial Warga Jotun. Jurnal ASPIKOM. 3(6). 1153-1162

Cangara, Hafied. (2018). Pengantar Ilmu Komunikasi Edisi Kedua. Jakarta: Raja Grafindo Persada

Koentjaraningrat. (1967). Beberapa Pokok Antropologi Sosial. Jakarta: Dian Rakyat Kuswarno, Engkus. (2009). Metode Penelitian Komunikasi: Fenomenologi, Konsepsi, Pedoman dan Contoh Penelitiannya. Bandung: Widya Padjajaran

Moleong, Lexy J. (2009). Metode Penelitian Kualitatif. Bandung: Remaja Rosdakarya Mulyana, Deddy dan Jalaluddin Rakhmat. (2010). Komunikasi Lintas Budaya. Bandung: Remaja Rosdakarya 